Kouwenhoven, P.S.C., Thiel, G.J.M.W. van, Raijmakers, N.J.H., Rietjens, J.A.C., Heide, A. van der, Delden, J.J.M. van. Euthanasia or physician-assisted suicide? A survey from the Netherlands. European Journal of General Practice: 2014, 20(1), 25-31

\begin{tabular}{|l|l|}
$\begin{array}{l}\text { Postprint } \\
\text { Version }\end{array}$ & 1.0 \\
\hline Journal website & http://informahealthcare.com/doi/abs/10.3109/13814788.2013.813014 \\
\hline Pubmed link & $\underline{\text { http://www.ncbi.nlm.nih.gov/pubmed/24359112 }}$ \\
\hline DOI & $10.3109 / 13814788.2013 .813014$ \\
\hline
\end{tabular}

This is a NIVEL certified Post Print, more info at http://www.nivel.eu

\title{
Euthanasia or physician-assisted suicide? A survey from the Netherlands
}

Pauline S. C. KouWenhoven 1, GHislaine J. M. W. VAN Thiel 1, NATASJa J. H. RAIJMAKERS 2, JUdith A. C. RIETJENS 2, AgNES VAN DER HEIDE 2 \& JOHANNES J. M. VAN DELDEN 1

${ }^{1}$ Julius Center for Health Sciences and Primary Care, University Medical Center Utrecht, the
Netherlands
${ }^{2}$ Department of Public Health, Erasmus Medical Center Rotterdam, the Netherlands

\begin{abstract}
Background: Legalizing euthanasia or physician-assisted suicide (PAS) is a current topic of debate in many countries. The Netherlands is the only country where legislation covers both.

Objectives: To study physicians' experiences and attitudes concerning the choice between euthanasia and PAS.

Methods: A questionnaire including vignettes was sent to a random sample of 1955 Dutch general practitioners, elderly care physicians and medical specialists.

Results: In total, 793 physicians (41\%) participated. There was no clear preference for euthanasia (36\%) or PAS (34\%). Two thirds of physicians thought that PAS underlines the autonomy and responsibility of the patient and considered this a reason to choose PAS. Reasons for not choosing PAS were expected practical problems. A minority (22\%) discussed the possibility of PAS with their patient in case of a request for assistance in dying. Patients receiving PAS more often experienced psychosocial suffering in comparison with patients receiving euthanasia. In vignettes of patients with a request for assistance in dying due to psychosocial suffering, physicians agreed more often with the performance of PAS than with euthanasia.

Conclusion: Dutch physicians perceive a difference between euthanasia and PAS. Although they believe PAS underlines patient autonomy and responsibility, the option of PAS is rarely discussed with the patient. The more psychosocial in nature the patient's suffering, the more physicians choose PAS. In these cases, PAS seems to fulfil physicians' preferences to emphasize patient autonomy and responsibility. Expected technical problems and unfamiliarity
\end{abstract}


Kouwenhoven, P.S.C., Thiel, G.J.M.W. van, Raijmakers, N.J.H., Rietjens, J.A.C., Heide, A. van der, Delden, J.J.M. van. Euthanasia or physician-assisted suicide? A survey from the Netherlands. European Journal of General Practice: 2014, 20(1), 25-31

with PAS also play a role. Paradoxically, the choice for PAS is predominantly a physician's one.

\section{INTRODUCTION}

Legalizing physician-assisted death is a current topic of debate in many countries (1). Legislation regarding euthanasia has been put into effect in Belgium and Luxembourg, and physician-assisted suicide (PAS) has been legalized in the states of Oregon, Washington and Montana (US). The Netherlands is the only country where legislation covers both. In other countries and states, discussion is still on-going. Internationally, different factors may determine the debate focusing on euthanasia, PAS or other medical end-of-life decisions, such as legislation, culture and tradition (2-4). Euthanasia and PAS are different forms of physician-assisted death.

Euthanasia is the administering of lethal drugs by a physician to end a patient's life on the patient's explicit request. In PAS, the patient self-administers medication to end his or her life that was prescribed for this purpose by a physician (5). Both PAS and euthanasia are punishable under the Dutch Penal Code, but physicians will not be prosecuted if all legal criteria for due care are met and the case is reported to an assessment committee. These criteria are identical for PAS and euthanasia. In cases that are found to fall short of fulfilling these criteria, the punishment of PAS consists of a maximum of three years of imprisonment, whereas in case of euthanasia, this is 12 years. The main patient-related criteria for euthanasia and PAS are the presence of unbearable physical or psychosocial suffering that cannot be relieved, and the explicit voluntary, well-considered request of the patient.

Until recently, the Royal Dutch Medical Association (RDMA) declared a preference for PAS over euthanasia because this would best express the patient's own role and responsibility (6). In its recent position paper, no preference for one particular method has been stated (7). However, most cases of physician-assisted death in the Netherlands are cases of euthanasia. Since 1990, the proportion of euthanasia has been $1.7-2.8 \%$ of annual deaths and of PAS $0.1-0.2 \%$ (5).

The discrepancy between the former RDMA preference for PAS and the milder sentence for cases of PAS on the one hand, and the almost exclusive performance of euthanasia in practice on the other hand, is remarkable. In most other countries, the discussions concerning the legalization of physician-assisted death are about legalizing PAS and not euthanasia. Knowledge is lacking about why PAS is relatively little practiced in the Netherlands and how decision making takes place. We studied the experiences and attitudes of physicians regarding decision making between euthanasia and PAS, case-specific characteristics, and the role of the patient as perceived by physicians in the decision-making process.

\section{METHODS}

\section{Design and population}

A questionnaire was sent to a random sample of 500 general practitioners, 250 elderly care physicians and 1250 medical specialists (250 general internists, 250 cardiologists, 250 pulmonologists, 250 neurologists and 250 surgeons) of whom 1 955 were eligible to return the questionnaire. These groups of physicians are together 
Kouwenhoven, P.S.C., Thiel, G.J.M.W. van, Raijmakers, N.J.H., Rietjens, J.A.C., Heide, A. van der, Delden, J.J.M. van. Euthanasia or physician-assisted suicide? A survey from the Netherlands. European Journal of General Practice: 2014, 20(1), 25-31

with intensive care physicians and paediatricians (who are unlikely to perform euthanasia or PAS) involved in more than $95 \%$ of all deaths in the Netherlands (5). The questionnaire could be completed by mail or electronically over a four-month period (January to May 2010). Two reminders were sent.

\section{Questionnaire}

The questions were part of a more extensive questionnaire on the knowledge and opinions of public and professionals concerning end-of-life decisions (KOPPEL study) (8). The questionnaire was pretested for length, comprehensibility and feasibility for online use among 10 physicians. These pilots resulted in minor adjustments.

The questionnaire included open and tick box questions and addressed respondent characteristics as well as experiences and opinions regarding euthanasia and PAS. Respondent characteristics included age, gender, specialism, years of working experience, attitude towards euthanasia and PAS and experience with performing euthanasia or PAS. We asked if, in general, physicians had a preference for euthanasia or PAS, provided the legal criteria are met, and both would be technically possible. We asked respondents, which of seven statement(s) could be a reason for them to choose PAS over euthanasia and vice versa. Furthermore, we asked physicians if they had performed physician-assisted death in the last five years. We asked for the diagnosis and main cause of suffering of this (most recent) patient and if they performed euthanasia or PAS in this case. If the physician had performed euthanasia, we asked if they had discussed the possibility of PAS with the patient and if not, why not. If they discussed the possibility of PAS, but euthanasia was performed, we asked why euthanasia had been chosen. Finally, respondents were asked about their opinions regarding unbearable suffering as a reason for euthanasia versus PAS as presented in different vignettes (Box 1). One out of five vignettes was randomly assigned to every respondent. Each vignette described the case of a patient who requested PAS and ultimately had PAS performed by a physician. We asked if in this case, the respondent personally agreed with the performance of PAS and if the respondent would assess the situation differently if it would concern euthanasia instead of PAS.

Box 1. Vignettes of patients requesting physician-assisted suicide: different cases of suffering.

A Mrs A (60 years old) has breast cancer with metastases. Despite undergoing several treatments, her disease is no longer curable. She is in severe pain that cannot be sufficiently relieved. In addition, she dislikes the feeling of loss of control that she experiences. In her working days, she always felt in control. She indicates that she cannot take it anymore. She asks her general practitioner for physician-assisted suicide. The general practitioner decides to honour her request and performs physician-assisted suicide.

B Mrs B (60 years old) has breast cancer with metastases. Despite undergoing several treatments, her disease is no longer curable. She has no physical symptoms at the moment. She dislikes the feeling of loss of control that she experiences. In her working days, she always felt in control. She indicates that she cannot take it anymore. She repeatedly asks her general practitioner for physician-assisted suicide. The general practitioner decides to honour her request and performs physicianassisted suicide. 
Kouwenhoven, P.S.C., Thiel, G.J.M.W. van, Raijmakers, N.J.H., Rietjens, J.A.C., Heide, A. van der, Delden, J.J.M. van. Euthanasia or physician-assisted suicide? A survey from the Netherlands. European Journal of General Practice: 2014, 20(1), 25-31

C Mrs C is middle-aged. She is physically well, but mentally ill. She has been suffering from severe depression for years, and her psychiatrist's treatment has not worked. She regularly tells her physicians that she wants to die. She already has had one unsuccessful suicide attempt. Mrs C visits her psychiatrist and repeatedly asks for physician-assisted suicide. The psychiatrist decides to honour her request and performs physician-assisted suicide.

D Mrs D is 65 years old. She suffers from early dementia and sometimes she is forgetful. She fears what is to come, the progressive loss of memory and the moment she will not recognize her surroundings anymore. Her own mother suffered from severe dementia, and she absolutely does not want to experience this process herself. Mrs D repeatedly asks her general practitioner for physician-assisted suicide. The general practitioner decides to honour her request and performs physician-assisted suicide.

E Mr E is 86 years old. He used to be a professor at the university. He enjoyed his life at that time. He neither married nor had children. Now he has grown old; many of his friends died. He often feels lonely. He is in good physical and mental condition. Though Mr E is aware that he could live for many years, he fears this. He would rather be dead and has told his general practitioner this several times. Mr E repeatedly asks his general practitioner for physician-assisted suicide. The general practitioner decides to honour his request and performs physician-assisted suicide. ${ }^{\text {a }}$ ${ }^{a}$ E: Illegal according to the Dutch Euthanasia Act (2002).

\section{Statistical analysis}

Data from the questionnaire (including vignettes) were analysed with descriptive statistics using SPSS 17.0. Valid percentages are presented in the tables; missing values did not exceed 5\%. $P$-values were calculated with $\chi^{2}$-testing. For each group of physicians, a weighting factor was calculated to make the results representative for all physicians in the Netherlands. Answers to open questions were analysed and categorized by two researchers independently (PK, GvT) and discussed until agreement was reached (PK, GvT and JvD).

\section{RESULTS}

\section{Respondents' characteristics}

In total, 793 physicians completed the questionnaire (response 41\%) of whom 224 general practitioners (response 46\%), 131 elderly care physicians (response 53\%) and 389 medical specialists (response 32\%). Characteristics are shown in Table 1. General practitioners had almost twice as often experience with the performance of euthanasia or PAS as compared to elderly care physicians and medical specialists ( $81 \%$ versus $41 \%$ and $44 \%$, respectively).

\section{[TABLE 1]}

\section{Physicians' preferences for euthanasia or PAS}

Overall, 36\% of physicians preferred euthanasia over PAS, 34\% preferred PAS and $25 \%$ had no preference. When physicians were confronted with several statements and asked, which statement(s) could be a reason for them to choose for PAS over euthanasia, 67-69\% agreed with the statements 'PAS underlines the patient's autonomy, free choice and/or own responsibility.’ Approximately one third 
Kouwenhoven, P.S.C., Thiel, G.J.M.W. van, Raijmakers, N.J.H., Rietjens, J.A.C., Heide, A. van der, Delden, J.J.M. van. Euthanasia or physician-assisted suicide? A survey from the Netherlands. European Journal of General Practice: 2014, 20(1), 25-31

considered (one or more of) the following statements a reason for choosing PAS: PAS entails less psychological burden (39\%); less burden in performance (39\%) for the physician, or PAS can provide a less abrupt dying process (35\%). Reasons for choosing euthanasia included: 'It can take a long time until death occurs in PAS (for the patient) (53\%).' 'I think many patients cannot take the lethal drink by themselves' (48\%),' 'It can take a long time until death occurs in PAS (for the physician)' (46\%) and 'I think the lethal drink is unreliable (39\%).' Similar reasons were given for choosing euthanasia over PAS in cases of actually performed euthanasia where the possibility of PAS had been discussed (Table 2).

\section{[TABLE 2]}

\section{Discussing the possibility of PAS}

Twenty-two per cent of the respondents who had performed euthanasia in the last five years reported having discussed the possibility of PAS with the patient in the most recent case. Of respondents who had not discussed the option of PAS ( $n=154)$, $31 \%(n=56)$ reported that the physical inability of the patient to drink the lethal medicine was a reason for not discussing the possibility of PAS, $20 \%(n=36)$ that unfamiliarity with PAS was a reason, and $19 \%(n=35)$ stated unreliability of the method as a reason. Eighteen per cent $(n=33)$ had moral considerations for not discussing the option of PAS, for example, 'to burden the patient in this phase with the responsibility for physician-assisted suicide felt like walking away from my own responsibility.' Another $15 \%(n=28)$ stated that the (presumed) patient's wish was euthanasia (Table 3).

\section{[TABLE 3]}

\section{Characteristics of performed cases of euthanasia and PAS}

In $85 \%$ of cases of performed euthanasia, the diagnosis was cancer, versus $67 \%$ in PAS $(P=0.014)$. The reason for suffering was the absence of prospect of relief in $33 \%$ of euthanasia cases versus $11 \%$ of PAS cases. In cases in which PAS was performed, the diagnosis was more often 'physical disease, but not cancer' (37\% versus $16 \%, P=0.007$ ) and the suffering was more often psychosocial in nature, e.g. care dependency, loss of dignity and fear of losing control $(P=0.029)$ as compared to cases of euthanasia. Patients' age was not related to the performance of euthanasia or PAS (Table 4).

\section{[TABLE 4]}

\section{Interchangeability of PAS and euthanasia in different vignettes}

Eighty-four per cent of respondents who agreed with PAS in a reference case of a patient with cancer and uncontrollable pain $(n=118)$ would also agree with euthanasia in this same case. Sixty-nine per cent of respondents who agreed with PAS in a patient with cancer without physical complaints $(n=55)$ would also agree with euthanasia. In patients with severe depression and early stage dementia $(n=61$ and $n=43$ respectively), 43-47\% would also agree with euthanasia after having agreed with PAS, and $10 \%$ in a patient who was tired of living $(n=24)$ (Table 5). 
Kouwenhoven, P.S.C., Thiel, G.J.M.W. van, Raijmakers, N.J.H., Rietjens, J.A.C., Heide, A. van der, Delden, J.J.M. van. Euthanasia or physician-assisted suicide? A survey from the Netherlands. European Journal of General Practice: 2014, 20(1), 25-31

\section{[TABLE 5]}

\section{DISCUSSION}

\section{Main findings}

Physicians equally often have a preference for euthanasia as for PAS. Most physicians in this study agree that PAS underlines the patient's autonomy, free choice and/or own responsibility and that this could be a reason for them (the physicians) to choose for PAS instead of euthanasia. However, PAS as a possible alternative for euthanasia is often not discussed with the patient and hardly ever performed. A physician's preference for PAS is related to psychosocial suffering. Reasons for not discussing and performing PAS were mostly practical; 39\% of physicians reported that PAS entails less psychological burden. However, psychological aspects were not otherwise addressed.

\section{Strengths and limitations}

The unique situation of the Dutch legislation covering both euthanasia and PAS provides a good opportunity to study this subject. This study includes a large and representative sample of physicians. Moreover, the questionnaire consisted of a combination of different types of questions including statements and vignettes. However, possible selection bias should be taken into account. The response rate was rather low (41\%). Although the sample was representative for physicians of the involved groups in the Netherlands in terms of gender and working experience, physicians who have performed euthanasia or PAS before are probably slightly overrepresented. It is possible that especially physicians with experience and affinity with the discussion about euthanasia, PAS and other end-of-life decisions have participated in this study.

\section{Interpretation}

Physical versus psychosocial suffering. As in earlier studies, a physical component of suffering was significant for physicians to call it unbearable suffering and be willing to grant a euthanasia request (9). Apparently, the more the suffering is related to an incurable physical disease, the more physicians perceive it to be within the realm of their medical expertise and responsibility. They may choose euthanasia in these cases, to take away a practical burden for the patient. This is reflected by open answers physicians gave to the question why they did not discuss the option of PAS, about considering themselves responsible for a good death or being willing to take full responsibility. However, in case of primarily psychosocial suffering, a preference for PAS seems to fulfil a need for more active involvement of the patient. Autonomy and decision making. Physicians may justifiably link PAS with underlining autonomy and the patient taking more responsibility. After all, swallowing the lethal drink is more active than to have the physician administer drugs intravenously. However, to safeguard the patient's autonomy, the patient's preference should be taken into account. If physicians do not inform their patients about the options and do not ask for their preferences, they cannot be sure about the patient's true wishes. Therefore, physicians must discuss the option of PAS more often with their patients. Until now, the choice between PAS and euthanasia has primarily become the physician's choice and has turned out to be a choice predominantly for euthanasia. Physicians assigning themselves the more active role 
Kouwenhoven, P.S.C., Thiel, G.J.M.W. van, Raijmakers, N.J.H., Rietjens, J.A.C., Heide, A. van der, Delden, J.J.M. van. Euthanasia or physician-assisted suicide? A survey from the Netherlands. European Journal of General Practice: 2014, 20(1), 25-31

in decision making as well as in the dying process itself may be subject to the criticism of paternalism and medicalization. However, one third of physicians in this study agree on PAS being a good choice because it is less burdensome for the physician. Since the physician is the one who delivers this care and is ultimately responsible, it is defendable to give the physician a say in the decision for PAS or euthanasia. Internationally, legislation and presumably culture determine the choice for euthanasia (Belgium and Luxembourg), PAS (US) or assisted death outside the medical domain (Switzerland). Looking into the different possibilities and their characteristics can help other countries to make a well-considered decision. Technical problems in the performance of PAS. In a former study, OnwuteakaPhilipsen found that general practitioners and elderly care physicians preferred euthanasia to PAS because of limitations imposed by the patient's condition in 48$78 \%$ of cases (10). In this study, one third of physicians mentioned that physical inability of the patient to swallow the lethal drink was a reason for not discussing the option of PAS. Obviously, there are cases in which performing PAS is practically not feasible. However, our results show that among other reasons for not choosing PAS were the expected technical problems and unfamiliarity with PAS, which go beyond unfeasibility. This could have become a self-fulfilling prophecy. A study of Groenewoud et al., found complications in the performance of PAS in 7\% of cases versus in 3\% of cases of euthanasia and problems with completion (longer-thanexpected time to death, failure to induce coma, awakening of the patient after induced coma) in 16\% (PAS) and 6\% (euthanasia) of cases (11). Horikx et al., studied physician's experiences with the performance of euthanasia and PAS and found that in nearly $80 \%$ of cases of PAS the patient dies within one hour. Another $20 \%$ finally received euthanasia, because the time until death turned out to be longer than previously discussed with the patient to be acceptable. Vomiting was reported in only two out of 60 cases of PAS (12). A recent study of Lalmohamed et al., about the experiences of Dutch physicians with drugs used in euthanasia and PAS (2007-2009) reported bad taste, a large drinking volume and an unpredictable time until death as the most important problems in PAS (13). If in certain cases PAS is preferred and seems to be feasible, then problems should be taken seriously and properly addressed. The national RDMA/ RDPA (Royal Dutch Pharmacists Association) guideline on the performance of euthanasia and PAS (2012) contains information about anti-emetics and recommends the intravenous method of euthanasia in case the patient has not died within two hours after having finished the lethal drink (14).

\section{CONCLUSION}

Although most Dutch physicians think PAS underlines patient autonomy and responsibility, the option of PAS instead of euthanasia is often not discussed with the patient. Expected technical problems and unfamiliarity with PAS play a role. When a patient's suffering is more physical in nature, physicians tend to choose euthanasia. Especially in case of psychosocial suffering, PAS seems to fulfil physicians' preferences to emphasize patient autonomy and responsibility. Paradoxically, the choice for PAS is predominantly a physician's one. 
Kouwenhoven, P.S.C., Thiel, G.J.M.W. van, Raijmakers, N.J.H., Rietjens, J.A.C., Heide, A. van der, Delden, J.J.M. van. Euthanasia or physician-assisted suicide? A survey from the Netherlands. European Journal of General Practice: 2014, 20(1), 25-31

\section{ACKNOWLEDGEMENTS}

The authors should like to thank all respondents who participated in this study of the KOPPEL-consortium. KOPPEL is a study on knowledge, attitudes and opinions of public and professionals on end-of-life decisions.

\section{FUNDING}

This study was supported by a grant from the Ministry of Health, Welfare and Sports. The sponsors approved the study design, but were not involved in the collection, analysis and interpretation of data.

\section{Declaration of interest:}

The authors report no conflicts of interest. The authors alone are responsible for the content and writing of the paper.

\section{REFERENCES}

1. Schuklenk U, van Delden JJ, Downie J, McLean SA, Upshur R, Weinstock D. Endof-life decision-making in Canada: The report by the Royal Society of Canada expert panel on end-of-life decision-making. Bioethics 2011;Suppl. 1:1-73.

2. Maitra RT, Harfst A, Bjerre LM, Kochen MM, Becker A. Do German general practitioners support euthanasia?Results of a nation-wide questionnaire survey. Eur J Gen Pract. 2005;11:94-100.

3. Anquinet L, Rietjens JA, Van den Block L, Bossuyt N, Deliens L. General practitioners' report of continuous deep sedation until death for patients dying at home: A descriptive study from Belgium. Eur J Gen Pract. 2011;17:5-13.

4. S. Bremberg TN. The variety of ethical issues in everyday practice. Interviews with Swedish GPs. Eur J Gen Pract. 2001;7:143-7.

5. Onwuteaka-Philipsen BD, Brinkman-Stoppelenburg A, Penning C, de Jong-Krul GJ, van Delden JJ, van der Heide A. Trends in end-of-life practices before and after the enactment of the euthanasia law in the Netherlands from 1990 to 2010: A repeated cross-sectional survey. Lancet 2012;380:908-15.

6. RDMA. Standpunt Federatiebestuur KNMG inzake euthanasie 2003. 2003:4 Available at: http://knmg.artsennet.nl/Publicaties/KNMGpublicatie/StandpuntFederatiebestuur-KNMG-inzake- euthanasie-2003.htm (accessed 16 July 2012).

7. RDMA. The role of the physician in the voluntary termination of life, RDMA, June 2011. Available at: http://knmg.artsennet.nl/Publicaties/KNMGpublicatie/Positionpaper-The-role-of-the-physician-in-the-voluntary-termination-of-life-2011.htm (accessed 16 July 2012).

8. Kouwenhoven PS, Raijmakers NJ, Delden JJ, Rietjens J, Schermer MH, van Thiel GJ, et al. Opinions of health care professionals and the public after eight years of euthanasia legislation in the Netherlands: A mixed method approach. Palliat Med. 2013;27;273-80.

9. van Tol D, Rietjens J, van der Heide A. Judgment of unbearable suffering and willingness to grant a euthanasia request by Dutch general practitioners. Health Policy 2010;97:166-72.

10. Onwuteaka-Philipsen BD, Muller MT, van der Wal G, van Eijk JT, Ribbe MW. Active voluntary euthanasia or physician-assisted suicide?J Am Geriatr Soc. 1997;45:1208-13.

11. Groenewoud JH, van der Heide A, Onwuteaka-Philipsen BD, Willems DL, van der Maas PJ, van der Wal G. Clinical problems with the performance of euthanasia and physician-assisted suicide in The Netherlands. N Engl J Med. 2000;342:551-6.

12. Horikx A, Admiraal PV. Utilization of euthanatic agents; experience of physicians with 227 patients, 1998-2000. Ned Tijdschr Geneeskd. 2000;144:2497-500.

13. Lalmohamed A, Horikx A. Experience with euthanasia since 2007. Analysis of problems with execution. Ned Tijdschr Geneeskd. 2010;154:A1882. 
Kouwenhoven, P.S.C., Thiel, G.J.M.W. van, Raijmakers, N.J.H., Rietjens, J.A.C., Heide, A. van der, Delden, J.J.M. van. Euthanasia or physician-assisted suicide? A survey from the Netherlands. European Journal of General Practice: 2014, 20(1), 25-31

14. RDMA. Richtlijn uitvoering euthanasie en hulp bij zelfdoding, KNMG and KNMP, 2012. 2012. Available at: http://knmg.artsennet.nl/Publicaties/KNMGpublicatie/Richtlijn-Uitvoering-euthanasieen-hulp-bij-zelfdoding-2012.htm (accessed 6 April 2013).

TABLES

Table 1. Background characteristics of respondents.

\begin{tabular}{|c|c|c|c|c|}
\hline & \begin{tabular}{|c} 
General \\
practitioners $n=$ \\
224 \\
\end{tabular} & \begin{tabular}{|c} 
Elderly care \\
physicians $n=$ \\
131 \\
\end{tabular} & \begin{tabular}{|c|} 
Medical \\
specialists $n=$ \\
389 \\
\end{tabular} & $\begin{array}{c}\text { Total }^{\mathrm{a}} \\
n=793\end{array}$ \\
\hline \multicolumn{5}{|l|}{ Age } \\
\hline Mean \pm SD & $50 \pm 8$ & $48 \pm 9$ & $53 \pm 8$ & $51 \pm 8$ \\
\hline \multicolumn{5}{|l|}{ Gender (\%) } \\
\hline Female & $39^{c}$ & $64^{\mathrm{d}}$ & $22^{\mathrm{e}}$ & 35 \\
\hline \multicolumn{5}{|l|}{$\begin{array}{l}\text { Years of working } \\
\text { experience }(\%)^{b}\end{array}$} \\
\hline 2-5 years & 4 & 17 & 6 & 6 \\
\hline $5-10$ years & 18 & 18 & 14 & 16 \\
\hline$>10$ years & 79 & 66 & 80 & 78 \\
\hline \multicolumn{5}{|l|}{\begin{tabular}{|l} 
Attitude towards \\
euthanasia and \\
physician-assisted \\
suicide (\%) \\
\end{tabular}} \\
\hline Liberal & 49 & 30 & 44 & 45 \\
\hline Reserved & 44 & 62 & 50 & 48 \\
\hline Against & 7 & 8 & 6 & 7 \\
\hline \multicolumn{5}{|l|}{\begin{tabular}{|l|} 
Performance of \\
euthanasia or physician- \\
assisted suicide $(\%)$
\end{tabular}} \\
\hline Ever performed & 81 & 41 & 44 & $63^{f}$ \\
\hline Performance thinkable & 11 & 45 & 45 & 28 \\
\hline $\begin{array}{l}\text { Performance } \\
\text { unthinkable }\end{array}$ & 8 & 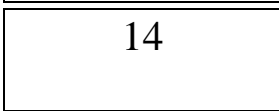 & 11 & 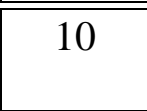 \\
\hline
\end{tabular}

${ }^{a}$ Weighted percentages, the specialty of 49 physicians was unknown.

${ }^{b}$ Respondents: (1) work in the Netherlands, (2) have at least two years of experience in their current specialty, (3) if retired, have been retired no longer than two years prior to participation or be under 67 years of age.

${ }^{\mathrm{c}} 40 \%$ female general practitioners in the Netherlands (Nivel, Netherlands Institute for Health Services Research, 2010). 
Kouwenhoven, P.S.C., Thiel, G.J.M.W. van, Raijmakers, N.J.H., Rietjens, J.A.C., Heide, A. van der, Delden, J.J.M. van. Euthanasia or physician-assisted suicide? A survey from the Netherlands. European Journal of General Practice: 2014, 20(1), 25-31

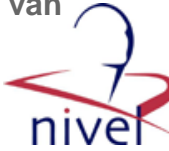

${ }^{\mathrm{d}} 61 \%$ female elderly care physicians in the Netherlands (Dutch Capacity Organ, 2009).

$34 \%$ female medical specialists of all specialties in the Netherlands (Dutch Capacity Organ, 2010).

${ }_{5} 51 \%$ ever performed and 33\% thinkable (Report on the evaluation of the Dutch euthanasia act, 2005). 
Kouwenhoven, P.S.C., Thiel, G.J.M.W. van, Raijmakers, N.J.H., Rietjens, J.A.C., Heide, A. van der, Delden, J.J.M. van. Euthanasia or physician-assisted suicide? A survey from the Netherlands. European Journal of General Practice: 2014, 20(1), 25-31

Table 2. Physicians' attitudes on reasons for choosing PAS or euthanasia (percentages).

\begin{tabular}{|c|c|c|c|c|c|}
\hline & $\begin{array}{c}\text { General } \\
\text { practitioners }\end{array}$ & \begin{tabular}{|c|} 
Elderly \\
care \\
physicians
\end{tabular} & \begin{tabular}{|c||} 
Medical \\
specialists
\end{tabular} & Total $^{\mathrm{a}}$ & \\
\hline & $n=224$ & $n=131$ & $n=389$ & $n=793$ & $P$-value \\
\hline $\begin{array}{l}\text { Reasons for } \\
\text { choosing PAS } \\
\text { over euthanasia }^{\text {b }}\end{array}$ & & & & & \\
\hline $\begin{array}{l}\text { I think PAS } \\
\text { underlines the } \\
\text { autonomy/free } \\
\text { choice/own } \\
\text { responsibility of } \\
\text { the patient } \\
\end{array}$ & $69 / 68 / 71$ & $73 / 65 / 67$ & $67 / 67 / 64$ & $69 / 67 / 68$ & $0.601 / 0.246 / 0.225$ \\
\hline \begin{tabular}{|l|} 
I consider PAS \\
psychologically \\
less burdensome \\
for the physician \\
\end{tabular} & 37 & 42 & 41 & 39 & 0.347 \\
\hline $\begin{array}{l}\text { PAS can provide } \\
\text { a less abrupt } \\
\text { dying process } \\
\end{array}$ & 42 & 29 & 28 & 35 & 0.002 \\
\hline \begin{tabular}{|l} 
I consider the \\
performance of \\
PAS less \\
burdensome for \\
the physician \\
\end{tabular} & 32 & 39 & 36 & 34 & 0.142 \\
\hline $\begin{array}{l}\text { I consider PAS } \\
\text { legally less } \\
\text { burdensome for } \\
\text { the physician } \\
\end{array}$ & 18 & 18 & 20 & 19 & 0.075 \\
\hline $\begin{array}{l}\text { Reasons for } \\
\text { choosing } \\
\text { euthanasia over } \\
\text { PAS }^{c} \\
\end{array}$ & & & & & \\
\hline \begin{tabular}{|l} 
It can take a long \\
time until death \\
occurs in PAS \\
(for the patient) \\
\end{tabular} & 66 & 42 & 39 & 53 & 0.000 \\
\hline $\begin{array}{l}\text { I think many } \\
\text { patients cannot } \\
\text { take the lethal } \\
\text { drink by } \\
\text { themselves }\end{array}$ & 55 & 53 & 38 & 48 & 0.000 \\
\hline
\end{tabular}


Kouwenhoven, P.S.C., Thiel, G.J.M.W. van, Raijmakers, N.J.H., Rietjens, J.A.C., Heide, A. van der, Delden, J.J.M. van. Euthanasia or physician-assisted suicide? A survey from the Netherlands. European Journal of General Practice: 2014, 20(1), 25-31

Table 2. Physicians' attitudes on reasons for choosing PAS or euthanasia (percentages).

\begin{tabular}{|c|c|c|c|c|c|}
\hline & $\begin{array}{c}\text { General } \\
\text { practitioners }\end{array}$ & \begin{tabular}{|c|} 
Elderly \\
care \\
physicians
\end{tabular} & \begin{tabular}{|c||} 
Medical \\
specialists
\end{tabular} & Total $^{\mathrm{a}}$ & \\
\hline & $n=224$ & $n=131$ & $n=389$ & $n=793$ & $P$-value \\
\hline $\begin{array}{l}\text { It can take a long } \\
\text { time until death } \\
\text { occurs in PAS } \\
\text { (for the } \\
\text { physician) } \\
\end{array}$ & 62 & 39 & 28 & 46 & 0.000 \\
\hline $\begin{array}{l}\text { I think the lethal } \\
\text { drink in PAS is } \\
\text { unreliable }\end{array}$ & 50 & 41 & 24 & 39 & 0.000 \\
\hline $\begin{array}{l}\text { I think the lethal } \\
\text { drink in PAS is } \\
\text { patient- } \\
\text { unfriendly } \\
\end{array}$ & 34 & 24 & 15 & 26 & 0.000 \\
\hline $\begin{array}{l}\text { I think many } \\
\text { patients do not } \\
\text { want to take the } \\
\text { lethal drink by } \\
\text { themselves } \\
\end{array}$ & 18 & 16 & 20 & 19 & 0.105 \\
\hline
\end{tabular}

${ }^{a}$ Weighted percentages, the specialty of 49 physicians was unknown.

${ }^{\mathrm{b}}$ The question was: 'Which of the following statements could be a reason for you to choose PAS over euthanasia?'

'The question was: 'Which of the following statements could be a reason for you to choose euthanasia over PAS?' 
Kouwenhoven, P.S.C., Thiel, G.J.M.W. van, Raijmakers, N.J.H., Rietjens, J.A.C., Heide, A. van der, Delden, J.J.M. van. Euthanasia or physician-assisted suicide? A survey from the Netherlands. European Journal of General Practice: 2014, 20(1), 25-31

Table 3. Reasons for not discussing the possibility of physician-assisted suicide instead of euthanasia.a

\begin{tabular}{|l|c|c|}
\hline & $\begin{array}{c}\text { Physicians } \\
\mathbf{1 5 4}^{\mathbf{c}} \mathbf{~} \mathbf{n}=\end{array}$ & $\begin{array}{c}\text { Number of times } \\
\text { mentioned }^{\mathbf{b}} \mathbf{n = 2 2 2} \mathbf{( \% )}\end{array}$ \\
\hline $\begin{array}{l}\text { Physical inability of the patient to } \\
\text { take the lethal drink in PAS }\end{array}$ & 31 & $56(25)$ \\
\hline Unfamiliarity with PAS & 20 & $36(16)$ \\
\hline $\begin{array}{l}\text { Unreliability of the method and lack } \\
\text { of control }\end{array}$ & 19 & $35(16)$ \\
\hline $\begin{array}{l}\text { Moral considerations of the } \\
\text { physician }\end{array}$ & 18 & 33 (15) \\
\hline Patient's wish & 15 & $28(13)$ \\
\hline Institutional setting & 4 & 8 (3) \\
\hline Miscellaneous & 15 & $26(12)$ \\
\hline \hline Total & 100 & $222(100)$ \\
\hline
\end{tabular}

${ }^{\mathrm{a}}$ Concerning the most recent case of a patient with an actual request for euthanasia or physician-assisted suicide in the last five years, only if euthanasia has been performed and the option of physician-assisted suicide had not been discussed (more than one answer possible).

${ }^{\mathrm{b}}$ Weighted percentages.

${ }^{\mathrm{c}}$ Of whom 63\% general practitioners. 
Kouwenhoven, P.S.C., Thiel, G.J.M.W. van, Raijmakers, N.J.H., Rietjens, J.A.C., Heide, A. van der, Delden, J.J.M. van. Euthanasia or physician-assisted suicide? A survey from the Netherlands. European Journal of General Practice: 2014, 20(1), 25-31

Table 4. Characteristics of cases of euthanasia and physician-assisted suicide.

\begin{tabular}{|c|c|c|}
\hline & \begin{tabular}{|c|}
$\begin{array}{c}\text { Euthanasia } n=250 \% \\
\text { (weighted) }\end{array}$ \\
\end{tabular} & $\begin{array}{c}\text { Physician-assisted suicide } n \\
=27 \% \text { (weighted) }\end{array}$ \\
\hline \multicolumn{3}{|l|}{ Diagnosis $^{\mathrm{a}}$} \\
\hline Cancer $^{\mathrm{b}}$ & 85 & 67 \\
\hline $\begin{array}{l}\text { Physical disease but not } \\
\text { cancer }^{c}\end{array}$ & 16 & 37 \\
\hline \multicolumn{3}{|l|}{ Main cause of suffering $^{d}$} \\
\hline $\begin{array}{l}\text { Physical complaint such as } \\
\text { pain or dyspnoea }\end{array}$ & 37 & 36 \\
\hline Fear for future suffering & 7 & 7 \\
\hline Care dependency & 6 & 11 \\
\hline Loss of dignity & 9 & 18 \\
\hline Fear of losing control & 2 & 7 \\
\hline $\begin{array}{l}\text { Absence of prospect of } \\
\text { relief }\end{array}$ & 33 & 11 \\
\hline
\end{tabular}

${ }^{\mathrm{a}}$ More than one answer was possible, in $<4 \%$ of cases it concerned a non-physical disease.

${ }^{\mathrm{b}} P=0.014$.

${ }^{\mathrm{c}} P=0.007$.

${ }^{\mathrm{d}} P=0.029\left(\chi^{2}\right.$-test); respondents were asked to choose one answer, if they gave more than one answer results are not shown. 
Kouwenhoven, P.S.C., Thiel, G.J.M.W. van, Raijmakers, N.J.H., Rietjens, J.A.C., Heide, A. van der, Delden, J.J.M. van. Euthanasia or physician-assisted suicide? A survey from the Netherlands. European Journal of General Practice: 2014, 20(1), 25-31

Table 5. Interchangeability of physician-assisted suicide with euthanasia in different cases of suffering.

\begin{tabular}{|l||c|c||c||c||c|}
\hline & $\begin{array}{c}\text { A Cancer } \\
\text { with loss } \\
\text { of control } \\
\text { and severe } \\
\text { pain }\end{array}$ & $\begin{array}{c}\text { B Cancer with } \\
\text { loss of control, } \\
\text { without } \\
\text { physical } \\
\text { symptoms }\end{array}$ & $\begin{array}{c}\text { C Severe } \\
\text { depression }\end{array}$ & $\begin{array}{c}\text { D Early } \\
\text { dementia }\end{array}$ & $\begin{array}{c}\text { E Old } \\
\text { age and } \\
\text { tired of } \\
\text { living }\end{array}$ \\
\hline $\begin{array}{l}\text { Respondents } \\
\text { personally agreeing } \\
\text { with performing } \\
\text { physician-assisted } \\
\text { suicide in this case }\end{array}$ & $n=118$ & $n=55$ & $n=61$ & $n=43$ & $n=24$ \\
\hline $\begin{array}{l}\text { Would you assess the } \\
\text { situation differently if } \\
\text { it would concern } \\
\text { euthanasia instead of } \\
\text { physician-assisted } \\
\text { suicide? }\end{array}$ & & & & & \\
\hline \hline Yes (\%) & $15(13)$ & $9(17)$ & $28(45)$ & $19(43)$ & $21(87)$ \\
\hline No (\%) & $97(84)$ & $38(69)$ & $26(43)$ & $21(47)$ & $2(10)$ \\
\hline \hline Don't know (\%) & $4(3)$ & $7(13)$ & $7(12)$ & $4(10)$ & $1(3)$ \\
\hline
\end{tabular}

